\title{
Inhibitory effects of adenovirus mediated COX-2, Akt1 and PIK3R1 shRNA on the growth of malignant tumor cells in vitro and in vivo
}

\author{
YANCHAO FU ${ }^{1}$, QINGYU ZHANG ${ }^{1}$, CHUNSHENG KANG $^{3}$, KAIRU ZHANG $^{2}$, JING ZHANG ${ }^{1}$, \\ PEIYU PU ${ }^{3}$, GUANGXIU WANG ${ }^{3}$ and TAO WANG ${ }^{1}$ \\ Departments of ${ }^{1}$ Gastroenterology, and ${ }^{2}$ Respiratory Medicine, Tianjin Medical University General Hospital, \\ Tianjin 300052; ${ }^{3}$ Department of Neurosurgery, Tianjin Medical University General Hospital and \\ Laboratory of Neuro-Oncology, Tianjin Neurological Institute, Tianjin 300052, P.R. China
}

Received March 26, 2009; Accepted June 5, 2009

DOI: 10.3892/ijo_00000369

\begin{abstract}
Cyclooxygenase-2 (COX-2) and phosphatidylinositol 3-kinase (PI3K)/Akt play a critical role in the formation of many malignant tumors, and have been shown to be important therapeutic targets. In the present study, small hairpin RNA (shRNA) expression constructs that target sequences of human COX-2, Akt1 and PIK3R1 were used to examine the proliferation and invasion inhibition effects on SGC7901 gastric adenocarcinoma cells and U251 glioma cells. Cell growth was inhibited by over $70 \%$, as indicated by a MTT assay, and was accompanied by G1/G0 phase arrest in the shRNA treated group, indicating poor cell growth activities. The number of cells invading through the matrigel in the shRNA treated group were significantly decreased (26.4 \pm 4.6$)$ compared with that of the control group $(105 \pm 4.0)$ and the nonsense sequence group $(102.5 \pm 6.4)$. In addition, the tumor volumes in the SGC7901 subcutaneous nude mouse model treated with shRNA was significantly smaller than those of the control group and nonsense sequence group. When COX2, Akt1 and PIK3R1 were dramatically downregulated, proliferating cell nuclear antigen (PCNA), CyclinD1 and matrix metalloproteinases (MMP-2, MMP-9) were downregulated, while tissue-inhibitor of metalloproteinase-2 (TIMP-2) and
\end{abstract}

Correspondence to: Dr Qingyu Zhang, Department of Gastroenterology, Tianjin Medical University General Hospital, 154 An-Shan Road, Heping District, Tianjin 300052, P.R. China

E-mail: zhangqy@tijmu.edu.cn

Dr Chunsheng Kang, Department of Neurosurgery, Tianjin Medical University General Hospital and Laboratory of Neuro-Oncology, Tianjin Neurological Institute, 154 An-Shan Road, Heping District, Tianjin 300052, P.R. China

E-mail: kang97061@yahoo.com

Key words: RNA interference, malignant tumor, proliferation, invasion, gene therapy
P53 were upregulated. Our results demonstrated that shRNA targeting COX-2, Akt1 and PIK3R1 downregulates their expression significantly in a sequence-specific manner, exerting proliferation and invasion inhibition effects on SGC7901 and U251 cells. In conclusion, our data suggest a novel mechanism for the regulation of malignant tumor cell growth and provide evidence for new combinatory gene therapy for malignant tumors.

\section{Introduction}

Tumor cell invasion and metastasis are the major causes of systemic cancer morbidity and mortality. Current therapeutic modalities include surgical resection, radiosurgical/external irradiation, chemotherapy and biological therapy, however, the overall prognosis is poor $(1,2)$. Single or multiple mutations in genes related to growth control, apoptosis, invasion and metastasis form the molecular genetic basis of malignant transformation and tumor progression (3). A better understanding of the molecular basis of tumor host interactions may help to achieve significant progress in the development of new therapeutic agents and new therapeutic approaches.

In recent years, RNA interference (RNAi) has been widely used to induce the sequence specific degradation of targeted mRNA. The double-stranded RNAs (dsRNA) are processed into small interfering RNAs (siRNAs) and mediate the suppression of homologous genes through a phylogenetically conserved cellular pathway via a two-step mechanism. In the first step, long dsRNAs are recognized by a nuclease in the RNase III family known as Dicer, which cleaves the dsRNA into siRNA of 21-23nt (4). These siRNAs are incorporated into a multicomponent nuclease complex, RNA-induced silencing complexes (RISC), that are responsible for the destruction of cognate mRNAs $(5,6)$. RNAi technology has been demonstrated to silence the targeted gene expression more efficiently and specifically, compared with the antisense approach (7-9). Recently, the application of RNAi for signaling molecules active in cancer has been shown to ameliorate the transformed phenotype in various tumors. Therefore, RNAi may be an effective approach for the treatment of various malignant tumors. 
Many tumors and tumor cell lines express elevated cyclooxygenase-2 (COX-2) protein levels that contribute to their malignant behavior (10). Epidemiologic studies indicate that chronic use of non-steroidal anti-inflammatory drugs that inhibit Cox-mediated production of prostaglandins is associated with lower incidence of a number of tumor types (11). Protective effects of COX inhibitors both in preventing tumor induction and inhibiting growth of transplanted tumors are well established (12-14). Several mechanisms underlie these therapeutic effects. Direct effects of COX inhibitors on tumor cells have been shown, including inhibition of cancer cell proliferation and induction of apoptosis (15). Other studies support an indirect effect of COX inhibitors on tumor angiogenesis (13). COX inhibitors are also effective at limiting metastatic disease $(12,14)$. In tumors, the principal COX-2 product is prostaglandin $\mathrm{E}_{2}\left(\mathrm{PGE}_{2}\right)$. Cellular effects of $\mathrm{PGE}_{2}$ are mediated through a family of G-protein-coupled receptors designated EP1, 2, 3 and EP4 (16). Despite structural and sequence similarities among the four E-series of prostaglandin (EP) receptors, they are coupled to different intracellular signaling pathways. Ligand binding of EP1 is associated with phospholipase $\mathrm{C}$ activation and elevations in intracellular calcium, whereas EP2 and EP4 are coupled to protein kinase A/adenyl cyclase and mediate elevations in intracellular cyclic AMP (cAMP). In addition to protein kinase A-coupled signaling, the EP4 receptor has also been shown to activate extracellular signal-regulated kinase (ERK) 1 and ERK2 by way of phosphatidylinositol 3-kinase (17). EP3 typically mediates decreases in intracellular cAMP, but cAMP-activating properties have also been ascribed to splice variants of this receptor subtype (18). PI3K/Akt is a major pathway for malignant progression in various tumors. The activation of the PI3K/AKT pathway is triggered by loss-of-function mutations of PTEN, which act as tumour suppressors, and has been noted in a wide range of cancers (19). One of the critical targets of AKT is mTOR, which plays a crucial role in PI3K-mediated oncogenesis (20). The kinase, mTOR, controls cell-cycle progression and cell size/mass through phosphorylation of proteins controlling protein translation (21). The activation of PI3K also plays a role in migration/ invasion, for example, in the process of IGF-I-induced migration of vascular smooth muscle cells (22). In addition, PI3K plays a crucial role in growth-factor-mediated trophoblast migration. The activation of PI3K using specific peptides results in an increase in the motility of SGHPL-5 evCTB cells, whereas the inhibition of PI3K retards basal and HGF-induced migration (23). The integrated action of PI3K in EGF-stimulated phosphorylation and the migration of HTR-8/SVneo evCTB cells have also been demonstrated (24). In the present study, we show that the suppression of COX-2, Akt1 and PIK3R1 expression using the COX-2, Akt1 and PIK3R1 small hairpin RNA (shRNA) RNAi approach mediated by adenovirus can inhibit SGC7901 and U251 tumor growth in vitro and in vivo, which may be an effective approach for the treatment of malignant tumors.

\section{Materials and methods}

The sequence of siRNA and constructs. The recombinant adenovirus vector that expresses shRNA against COX-2,
Akt1 and PIK3R1 (rAd5-C-A-P) was synthesized by Wuhan Genesil Co., Ltd. The sequence of the siRNA were as follows: COX2: sense 5'-AAC UGC UCA ACA CCG GAA Udtdt-3', anti-sense 5'-AUU CCG GUG UUG AGC AGU Udtdt-3'; AKT1: sense 5'-GGA GAU CAU GCA GCA UCG Cdtdt-3', anti-sense 5'-GCG AUG CUG CAU GAU CUC Cdtdt-3'; PIK3R1: sense 5'-GAA AGG AGG AAA UAA CAA Adtdt-3', anti-sense 5'-UUU GUU AUU UCC UCC UUU Cdtdt-3'. The nonsense sequence used for control was 5'-ACTACCGTTGT TATAGGTG-3'.

Cell culture and transfection. Human SGC7901 gastric adenocarcinoma cells and glioblastoma U251 cells were obtained from the Laboratory of Neuro-Oncology, Tianjin Neurological Institute of Tianjin Medical University General Hospital. The cells were cultured in Dulbecco's modified Eagle's medium (DMEM) (ATCC, Manassas, VA), supplemented with $10 \%$ fetal bovine serum (FBS) (Invitrogen, Carlsbad, CA), $100 \mu \mathrm{g} / \mathrm{ml}$ penicillin and $100 \mu \mathrm{g} / \mathrm{ml}$ streptomycin. The cells were maintained at $37^{\circ} \mathrm{C}$ in a humidified atmosphere with $5 \% \mathrm{CO}_{2}$. For gene transfection, $2 \times 10^{5}$ cells were placed into each well of 6-well plates and grown overnight until they were $50-80 \%$ confluent. The nutrient medium was changed to that without FBS, and rAd5-C-A-P was transfected into the cells (MOI=100). After four hours, the medium was changed to the complete medium. The cells were grouped as SGC7901 (Control), nonsense sequence (HK), and rAd5C-A-P (named $\mathrm{C}+\mathrm{A}+\mathrm{P}$ ).

Real-time PCR. Total RNA was extracted using TRIzol reagents (Life Technologies), according to the manufacturer's instructions. Isolated RNA was electrophoresed through $1.0 \%$ agarose-formaldehyde gels to verify the quality of the RNA. The first strand cDNA was generated by reverse transcription. After a sufficient amount of cDNA was obtained, we performed PCR amplification using a real-time PCR cycler (7500 ABI, USA). The sequences of PCR primers were: COX-2, 5'-GAAGTACCAAGCTGTGCTTGAATAA-3' and 5'-GGCTTGATTCCAATGCACCTA-3'; Akt1, 5'-GGCCCA GATGATCACCATCACR-3' and 5'-CTATCGTCCAGC GCAGTCCA-3'; PIK3R1, 5'-AGCATTGGGACCTCACAT TACACA-3' and 5'-ACTGGAAACACAGTCCATGCAC ATA-3'; GAPDH, 5'-CCACCCATGGCAAATTCC3' and 5'-GATGGGATTTCCATTGATGACA-3'.

Amplification system included $25 \mu 1$ of SYBR Green (12.5 $\mu \mathrm{l})$, ROXII0.5 $\mu \mathrm{l}(0.5 \mu \mathrm{l}), \mathrm{ddH}_{2} \mathrm{O}(10 \mu \mathrm{l})$, cDNA $(1 \mu \mathrm{l})$, forward primer $(0.5 \mu 1)$ and reverse primer $(0.5 \mu 1)$. The reaction conditions were as follows: Stage $1,95^{\circ} \mathrm{C}$ for $0.10 \mathrm{~min}$ (1 cycle); Stage $2,95^{\circ} \mathrm{C}$ for $0.05 \mathrm{~min}$ followed by $60^{\circ} \mathrm{C}$ for $0.34 \mathrm{~min}$ (40 cycles); Stage $3,95^{\circ} \mathrm{C}$ for $0.15 \mathrm{~min}$ followed by $60^{\circ} \mathrm{C}$ for $1.00 \mathrm{~min}$ and $95^{\circ} \mathrm{C}$ for $0.15 \mathrm{~min}(1 \mathrm{cycle})$. The results of real-time PCR were analyzed by the DDCt method: $\Delta \mathrm{Ct}=\mathrm{CT}_{\text {selected gene }}-\mathrm{CT}_{\mathrm{GAPDH}}, \Delta \Delta \mathrm{CT}=\Delta \mathrm{CT}_{\text {therapy group }}-$ $\Delta \mathrm{CT}_{\text {control group }}, \mathrm{RQ}$ (Relative Quantitation) $)_{\text {therapy group }}=2^{-\Delta \Delta \mathrm{CT}}$, $\mathrm{RQ}_{\text {control group }}=1$. The results of real-time PCR were presented as the ratio between the selected genes and GAPDH transcripts.

Western blot analysis. After transfection, individual clones were trypsinized and washed with ice-cold phosphate-buffered saline (PBS) three times. The cells were dissolved in $1 \%$ 
Nonidet P-40 lysis buffer (20 mM Tris, pH 8.0, $137 \mathrm{mM}$ $\mathrm{NaCl}, 1 \%$ Nonidet P-40, $10 \%$ glycerol, $1 \mathrm{mM} \mathrm{CaCl}, 1 \mathrm{mM}$ $\mathrm{MgCl}_{2}, 1 \mathrm{mM}$ phenylmethylsulfonyl fluoride, $1 \mathrm{mM}$ sodium fluoride, $1 \mathrm{mM}$ sodium orthovanadate, and a protease inhibitor mixture). Homogenates were clarified by centrifugation at $12,000 \mathrm{x} \mathrm{g}$ for $15 \mathrm{~min}$ at $4^{\circ} \mathrm{C}$ and protein concentrations were determined using a SuperSignal protein detection kit (Pierce, USA). Samples were made equal in protein concentration and volume, and then transferred to SDS-PAGE on $8 \%$ SDS-acrylamide gels. Separate proteins were transferred to PVDF membranes (Millipore, USA) followed by blocking. The membranes were incubated with the primary antibodies to COX-2, Akt1, PIK3R1, PCNA, CyclinD1, MMP-2, MMP-9, TIMP-2 and P53 (1:100 dilution, Santa Cruz Biotechnology), followed by incubation with HRP-conjugated secondary antibody (1:1000 dilution, Zymed). The specific protein was detected using a SuperSignal protein detection kit (Pierce). After washing with stripping buffer, the membrane was reprobed with antibody against $\beta$-actin (1:500 dilution, Santa Cruz Biotechnology) using the same procedures described above.

Flow cytometric analysis. Transfected and control cells in the log phase of growth were harvested by trypsinization. Cells were washed with PBS, fixed with ethanol and incubated with RNase at $37^{\circ} \mathrm{C}$ for $30 \mathrm{~min}$. Nuclei of cells were stained with propidium iodide for an additional $30 \mathrm{~min}$. A total of 10,000 nuclei were examined in a FACS Caliber flow cytometer (Becton-Dickinson, Heidelberg, Germany) and DNA histograms were analyzed by Modifit software.

MTT assay. Growth inhibition of rAd5-C-A-P was evaluated using a 3-[4,5-dimethylthiazol- 2-yl]-2,5-diphenyltetrazolium bromide (MTT, Sigma) assay. Briefly, $1 \times 10^{4}$ cells were placed in 96-well plates and grown overnight. Twenty $\mu 1$ of MTT (5 g/l) was added into each well for $4 \mathrm{~h}$. After the medium containing MTT was aspirated, the formazan crystals were dissolved in $200 \mu \mathrm{l}$ of dimethyl sulfoxide (DMSO). The absorbance was recorded using a Teacan 96-well spectrophotometer at a wavelength of $570 \mathrm{~nm}$, with a wavelength of $630 \mathrm{~nm}$ as the reference. The data are presented as the mean \pm SD derived from triplicate samples of at least three independent experiments.

Transwell invasion assay. The transwell filters (Costar, USA) were coated with matrigel $(3.9 \mu \mathrm{g} / \mu 1,60-80 \mu 1)$ on the upper surface of polycarbonate membrane (diameter $6.5 \mathrm{~mm}$, pore size $8 \mu \mathrm{m}$ ). After incubating at $37^{\circ} \mathrm{C}$ for $30 \mathrm{~min}$, matrigel became solidified and served as the extracellular matrix for tumor cell invasion analysis. Harvested cells $\left(1 \times 10^{5}\right)$ in $100 \mu 1$ of serum free DMEM were added into the upper compartment of the chamber. A total of $200 \mu \mathrm{l}$ of conditioned medium derived from NIH3T3 cells was used as a source of chemoattractant and placed in the bottom compartment of the chamber. After $24 \mathrm{~h}$ of incubation at $37^{\circ} \mathrm{C}$ with $5 \% \mathrm{CO}_{2}$, the medium was removed from the upper chamber. The non-invaded cells on the upper side of the chamber were scraped off with a cotton swab. The cells that had migrated from matrigel into the pores of the inserted filter were fixed with $100 \%$ methanol, stained with hematoxylin, mounted and dried at $80^{\circ} \mathrm{C}$ for $30 \mathrm{~min}$. The number of cells invading through the matrigel was counted using three randomly selected visual fields from the central and peripheral portion of the filter by an inverted microscope at magnification $\mathrm{x} 200$. Each assay was repeated three times.

Subcutaneous tumor model and gene therapy. Four-week-old female immune-deficient nude mice (BALB/c-nu) were purchased from the animal center of the Cancer Institute of Chinese Academy of Medical Sciences, bred at the facility of laboratory animals, Tianjin University, and housed in microisolator individually ventilated cages with water and food. All experimental procedures were carried out according to the regulations and internal biosafety and bioethics guidelines of Tianjin Medical University and the Tianjin Municipal Science and Technology Commission.

Four mice were injected subcutaneously with $1 \times 10^{8}$ of SGC7901 cells, in a volume of $50 \mu 1$ of PBS pre-mixed with equal volume of matrigel matrix (Becton-Dickinson). Mice were monitored on a daily basis. When the tumor size reached $\sim 5 \mathrm{~mm}$ in length, the tumors were surgically removed, cut into pieces of 1-2 $\mathrm{mm}^{3}$ and re-seeded in 30 mice individually. Again, when the tumor size reached $\sim 5 \mathrm{~mm}$ in length, the mice were randomly grouped as SGC7901 (Control), nonsense sequence (HK), rAd5-C-A-P (C+A+P). For the $\mathrm{HK}$ and $\mathrm{C}+\mathrm{A}+\mathrm{P}$ groups, $10 \mu \mathrm{l}$ adenovirus liquor was injected into the subcutaneous tumors using a multi-site injection method. A second administration was conducted on the third day using the same methods. The tumor volume was measured with a caliper, using the formula: volume = length $\mathrm{x}$ width $2 / 2$.

Immunohistochemistry. After 30 days, the mice were sacrificed and paraffin-embedded tissue sections were used for the examination of COX-2, Akt1, PIK3R1, PCNA, CyclinD1, MMP-2, MMP-9, TIMP-2 and P53 expression. Sections were dewaxed, treated with $3 \% \mathrm{H}_{2} \mathrm{O}_{2}$ for 10 min and incubated with appropriate antibody (1:200 dilutions) overnight at $4{ }^{\circ} \mathrm{C}$. Biotinylated secondary antibody (1:200 dilutions) was added at room temperature for $1 \mathrm{~h}$, followed by incubation with ABC-peroxidase for an additional hour. After washing with Tris-buffer, the sections were incubated with DAB (3,3'diaminobenzidine, $30 \mathrm{mg}$ dissolved in $100 \mathrm{ml}$ Tris-buffer containing $0.03 \% \mathrm{H}_{2} \mathrm{O}_{2}$ ) for $5 \mathrm{~min}$, rinsed in water and counterstained with hematoxylin.

Statistical analysis. A commercially available software package, SPSS10.0, was used for statistical analysis. Oneway analysis of variance (ANOVA) and $\chi^{2}$ test was used to analyze the significance between groups. The LSD method of multiple comparisons with parental and control vector groups was used when the probability for ANOVA was statistically significant. Statistical significance was determined at $\mathrm{P}<0.05$ level.

\section{Results}

The rAd5-C-A-P adenovirus expression vector. The rAd5-CA-P adenovirus expression vector was constructed, and is shown in Fig. 1. 


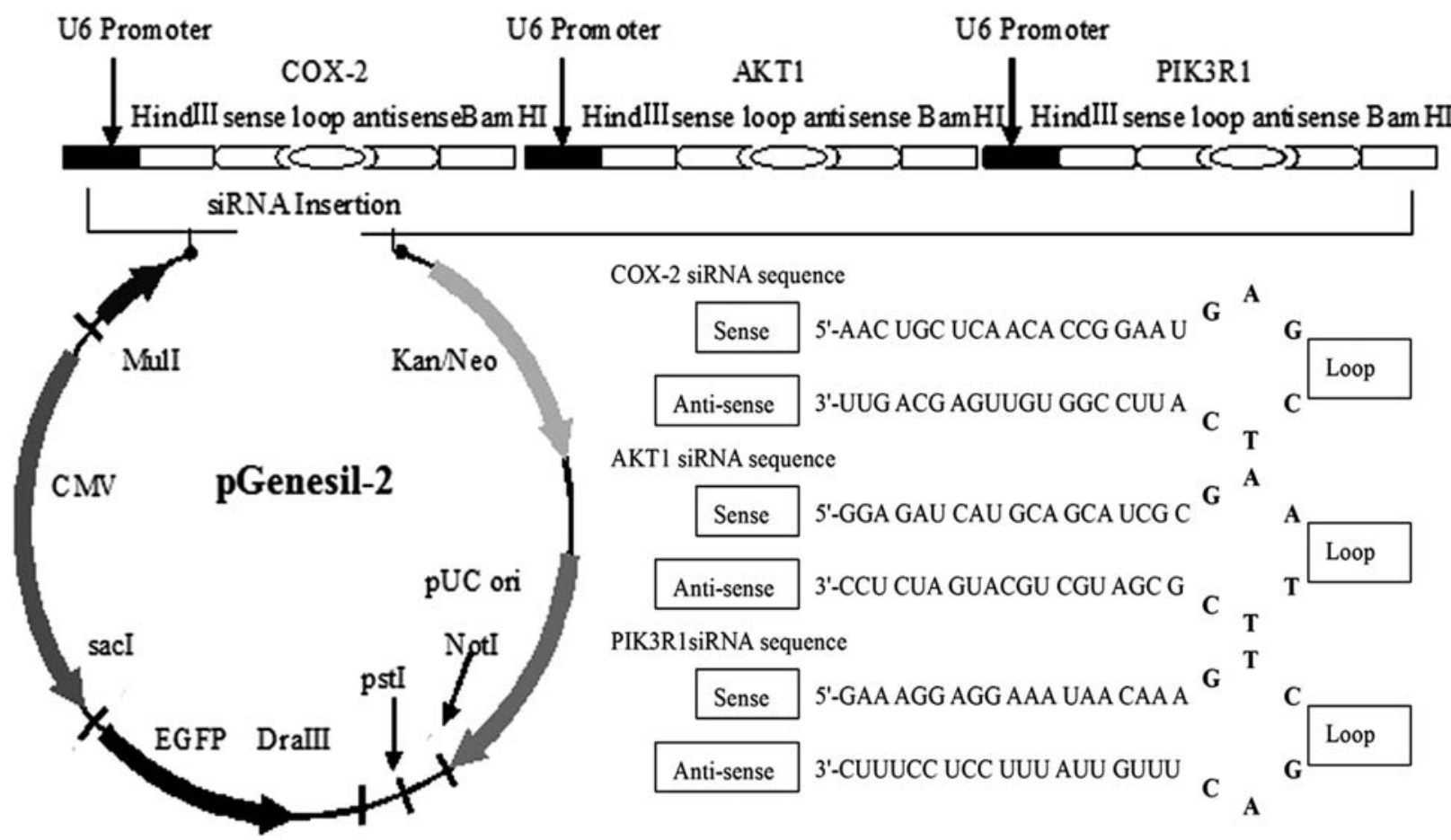

Figure 1. Schematic diagram of the plasmid vector. The sequence of siRNA: COX2: sense 5'-AAC UGC UCA ACA CCG GAA Udtdt-3', anti-sense 5'-AUU CCG GUG UUG AGC AGU Udtdt-3'; AKT1: sense 5'-GGA GAU CAU GCA GCA UCG Cdtdt-3', anti-sense 5'-GCG AUG CUG CAU GAU CUC Cdtdt-3'; PIK3R1: sense 5'-GAA AGG AGG AAA UAA CAA Adtdt-3', anti-sense 5'-UUU GUU AUU UCC UCC UUU Cdtdt-3'.
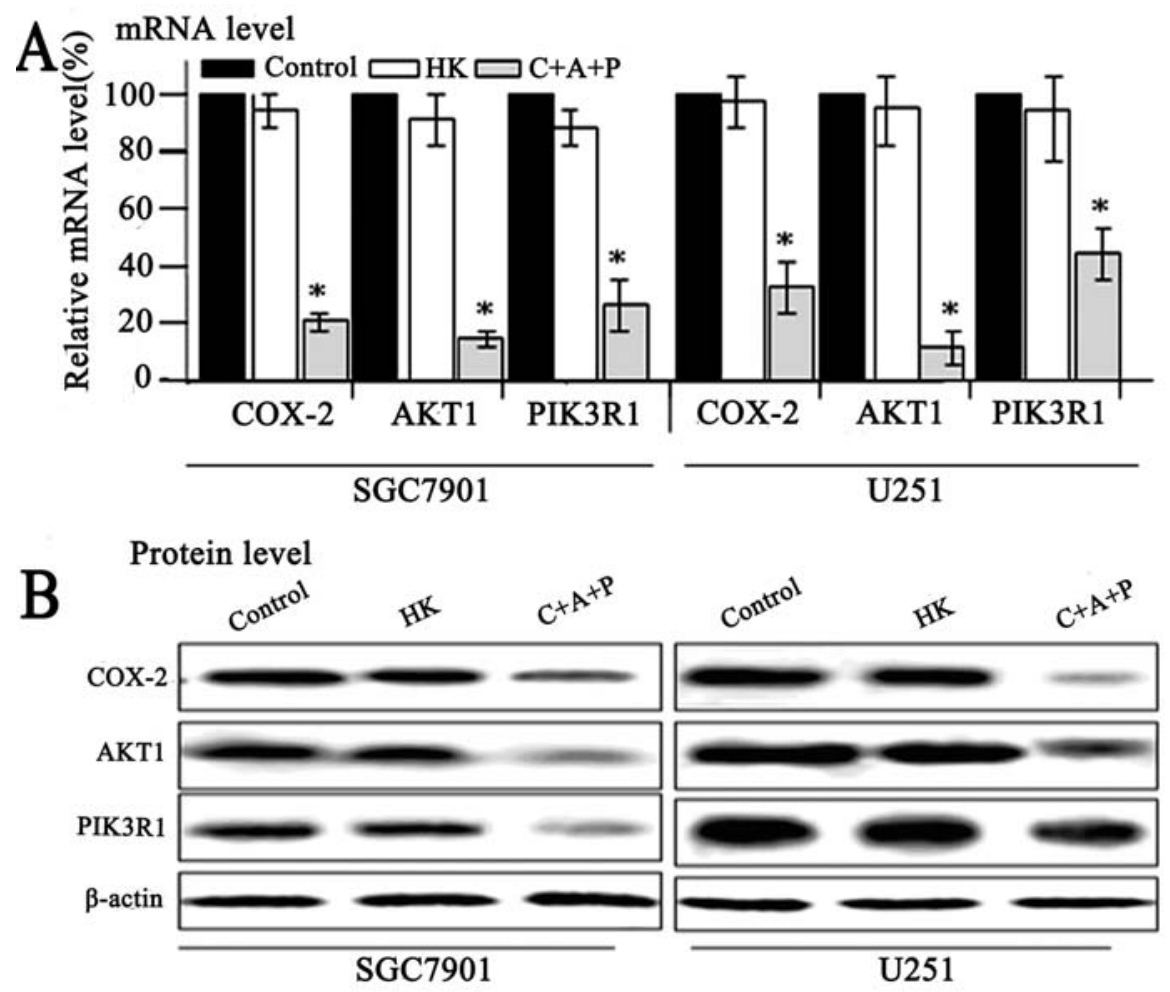

Figure 2. (A) mRNA level of COX-2, Akt1 and PIK3R1 after SGC7901 and U251 cells were treated with different shRNAs. (B) Protein level of COX-2, Akt1 and PIK3R1 after SGC7901 and U251 cells were treated with different shRNAs determined by Western blotting.

Suppression of COX-2, Akt1 and PIK3R1 expression by rAd5-C-A-P in SGC7901 and U251 cells. At $48 \mathrm{~h}$ after transfection of SGC7901, real-time PCR indicates the $\Delta \mathrm{Ct}$ of the selected genes, COX-2 (Control, 3.725 \pm 0.076 ; HK,
3.748 \pm 0.077 ; and $\mathrm{C}+\mathrm{A}+\mathrm{P}, 6.325 \pm 0.090$ ), Akt1 (Control, $10.574 \pm 0.016$; HK, $10.625 \pm 0.015$; and $\mathrm{C}+\mathrm{A}+\mathrm{P}, 12.791 \pm 0.057$ ) and PIK3R1 (Control, 10.903 \pm 0.148 ; HK, 10.979 \pm 0.148 ; and $\mathrm{C}+\mathrm{A}+\mathrm{P}, 12.863 \pm 0.138)$ (Fig. 2A). Compared with the results 

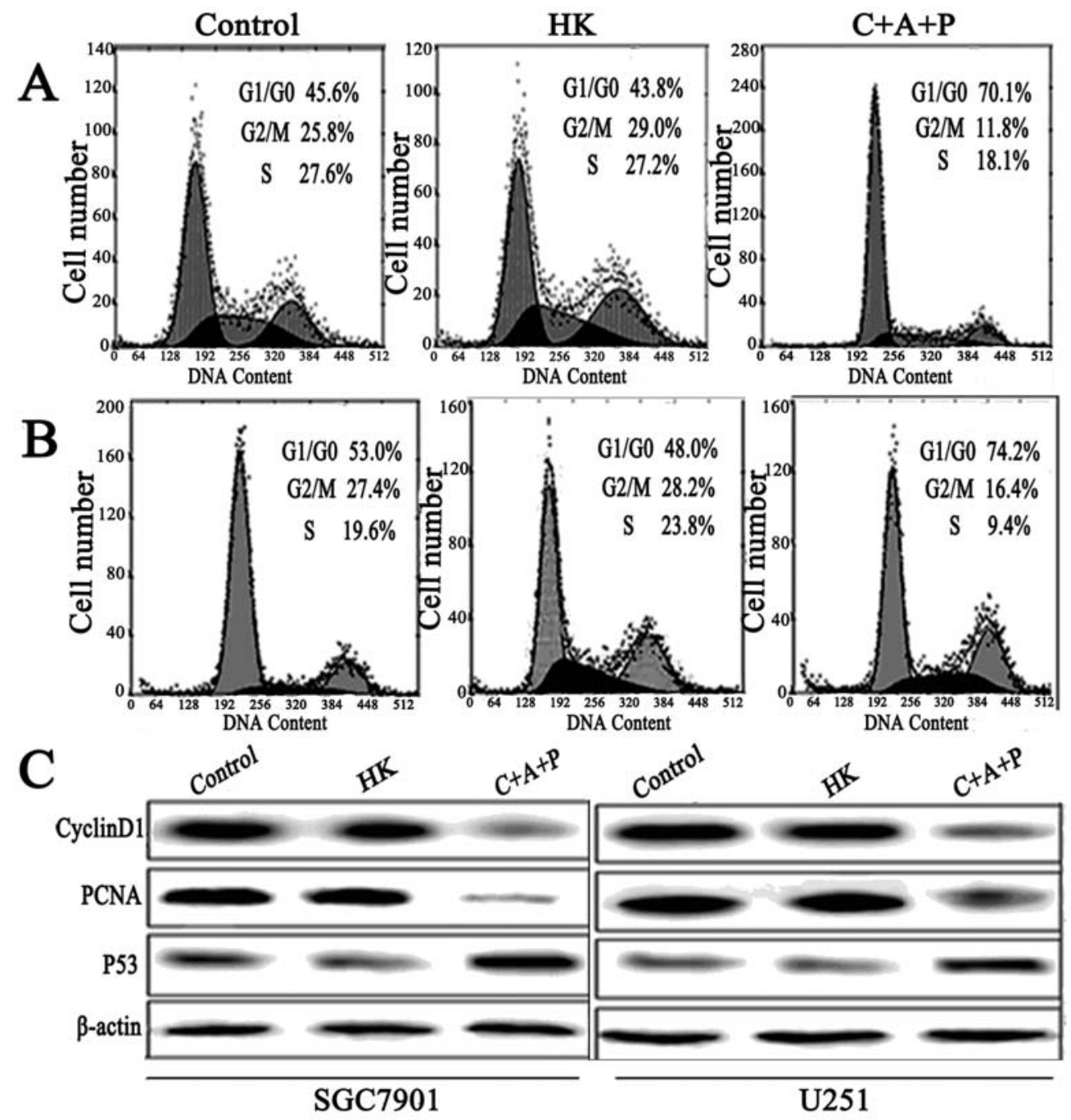

Figure 3. (A) Suppression of COX-2, Akt1 and PIK3R1 expression by rAd5-C-A-P in SGC7901 cells induces G1/G0 arrest and inhibits cell growth. Cell cycle distribution after transfection. (B) Suppression of COX-2, Akt1 and PIK3R1 expression by rAd5-C-A-P in U251 cells induces G1/G0 arrest and inhibits cell growth. Cell cycle distribution after transfection. (C) Protein level of CyclinD1, PCNA and P53 after SGC7901 and U251cells were treated with different shRNAs determined by Western blotting.

of the Control and HK group, the expression level of mRNA in the $\mathrm{C}+\mathrm{A}+\mathrm{P}$ group was suppressed $(\mathrm{COX}-2, \mathrm{~F}=1009.4$ and $\mathrm{P}<0.001 ; \mathrm{AKT} 1, \mathrm{~F}=3869.8$ and $\mathrm{P}<0.001 ; \mathrm{PIK} 3 \mathrm{R} 1, \mathrm{~F}=176.1$ and $\mathrm{P}<0.001)$. At $48 \mathrm{~h}$ after transfection of $\mathrm{U} 251$ cells, real-time PCR indicates the $\triangle \mathrm{Ct}$ of the selected genes, COX-2 (Control, 7.157 $\pm 0.108, \mathrm{HK}, 7.210 \pm 0.110$ and $\mathrm{C}+\mathrm{A}+\mathrm{P}, 10.048 \pm 0.107$ ), Akt1 (Control, 8.525 \pm 0.167 ; HK, $8.544 \pm 0.168$; and $\mathrm{C}+\mathrm{A}+\mathrm{P}, 10.491 \pm 0.165)$ and PIK3R 1 (Control, 4.26 \pm 0.112 ; HK, 4.273 \pm 0.113 ; and $\mathrm{C}+\mathrm{A}+\mathrm{P}$, $5.746 \pm 0.123$ ) (Fig. 2A). Compared with the results of the Control and HK group, the expression level of mRNA in $\mathrm{C}+\mathrm{A}+\mathrm{P}$ group was suppressed $(\mathrm{COX}-2, \mathrm{~F}=697.4$ and $\mathrm{P}<0.001$; Akt1, $\mathrm{F}=137.9$ and $\mathrm{P}<0.001 ; \mathrm{PIK} 3 \mathrm{R} 1, \mathrm{~F}=162.6$ and $\mathrm{P}<0.001)$.

Western blotting confirmed the suppression of COX-2, Akt1 and PIK3R1 protein expression in rAd5-C-A-P transfected cells, comparing with the Control and HK groups $(\mathrm{P}<0.001)$. No difference was observed between the Control and HK groups (P>0.05). COX-2, Akt1 and PIK3R1 expression were downregulated dramatically by approximately $53.8,20.31$ and $38.46 \%$, respectively, in the $\mathrm{C}+\mathrm{A}+\mathrm{P}$ group compared with that of the Control and HK groups (Fig. 2B).
In addition, PCNA, CyclinD1, MMP-2 and MMP-9 were downregulated by $30.32,23.56,47.54$ and $19.62 \%$, respectively. However, TIMP-2 and P53 were upregulated by $\sim 182.90$ and $162.44 \%$, respectively (Figs. 3C and 5D). In U251 cells, COX-2, Akt1 and PIK3R1 expression was downregulated by $\sim 13.2,26.6$ and $34.9 \%$, respectively, in the $\mathrm{C}+\mathrm{A}+\mathrm{P}$ group compared with the Control and HK groups (Fig. 2B). In addition, PCNA, CyclinD1, MMP-2 and MMP-9 were downregulated by $20.34,17.34,37.65$ and $15.60 \%$, respectively. TIMP-2 and P53 were upregulated by $\sim 192.45$ and $182.65 \%$, respectively (Figs. 3C and 5D).

Effect of COX-2, Akt1 and PIK3R1 knocked-down on SGC7901 and U251 cells proliferation. The cell cycle distribution of control and transfected cells was analyzed by flow cytometry. In SGC7901 cells, as shown in Fig. 3A, the G1/G0 phase fraction of the Control and HK groups was 45.6 and $43.8 \%$, respectively, while the $\mathrm{C}+\mathrm{A}+\mathrm{P}$ group increased to $70.1 \%$. The $\mathrm{S}$ phase fraction in the Control and HK groups was 27.2 and $27.6 \%$, respectively, but decreased significantly in the $\mathrm{C}+\mathrm{A}+\mathrm{P}$ group to $18.1 \%$. In U251 cells, as shown in Fig. 3B, 

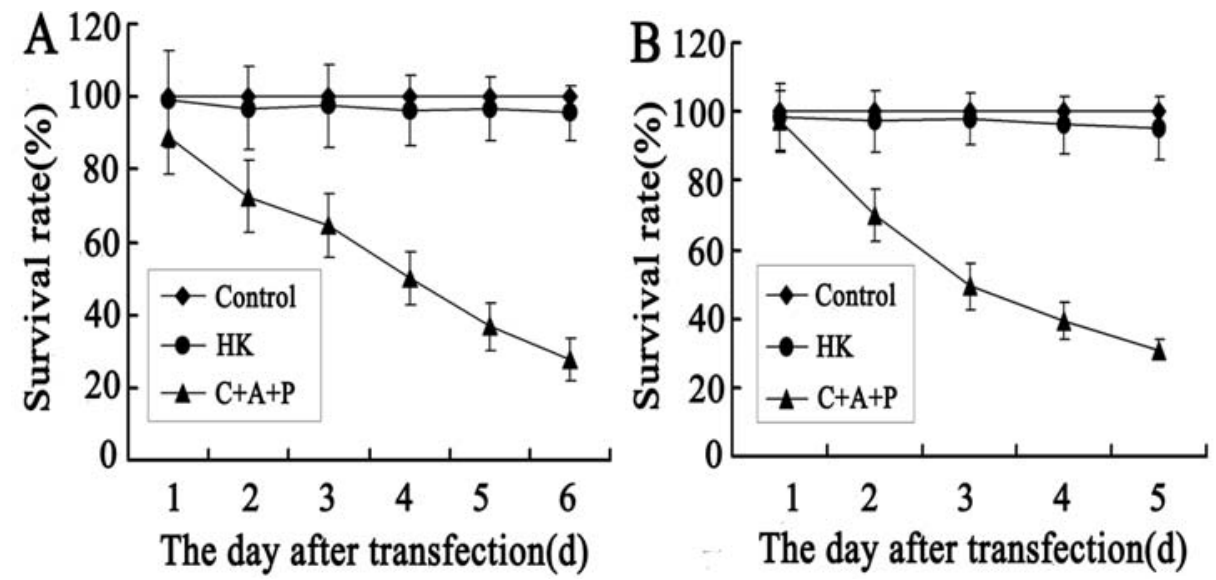

Figure 4. Transfected and control SGC7901 (A) and U251 cells (B) $\left(2 \times 10^{3}\right.$ per well) were plated into 96-well plate in the Control, $\mathrm{HK}$ and C+A+P groups The latitudinal axis represents days after cell implantation in the 96 -well plate. The survival rate in the Control group is presented as $100 \%$.

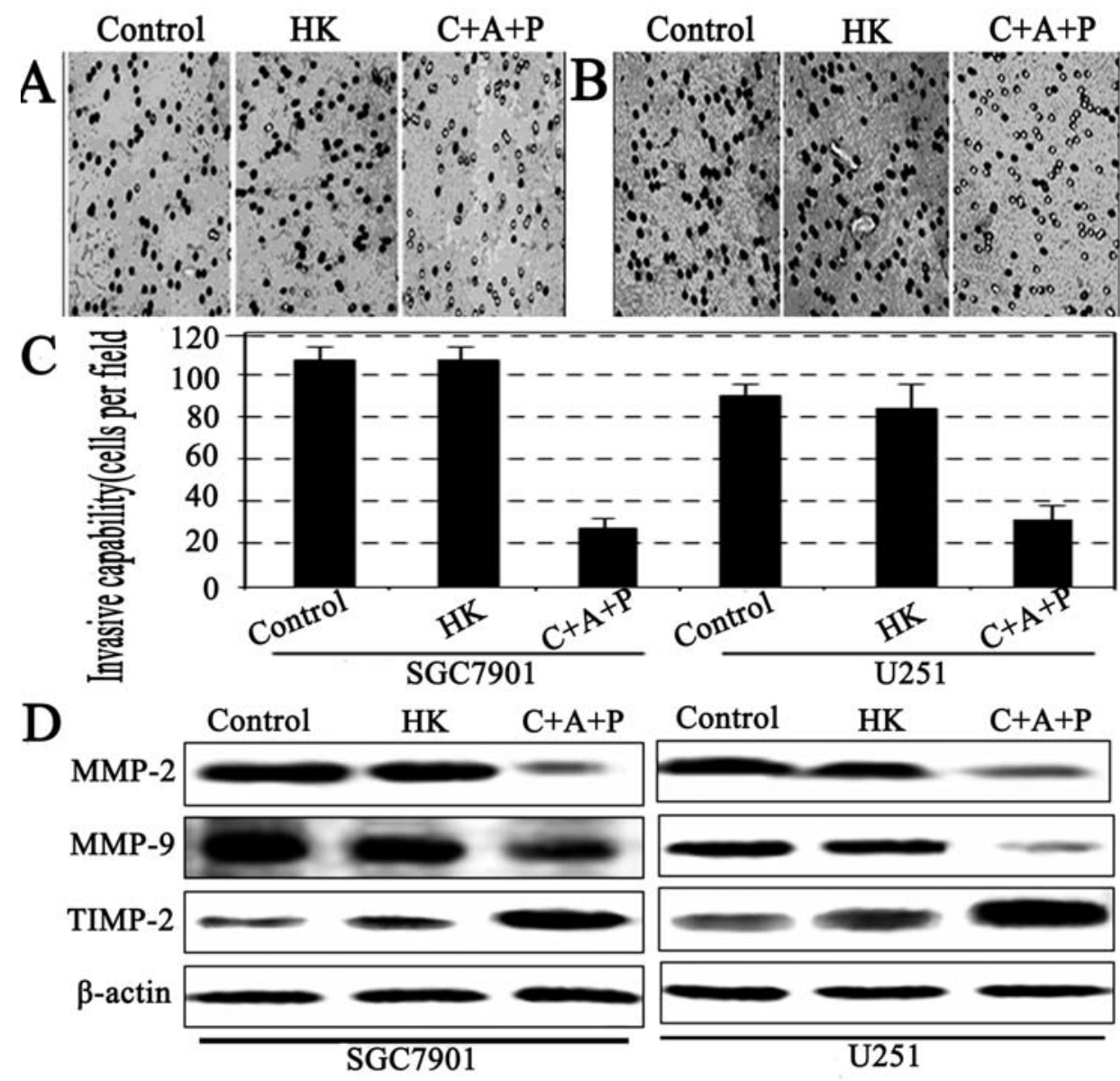

Figure 5. Invasive capability of the Control, $\mathrm{HK}$ and $\mathrm{C}+\mathrm{A}+\mathrm{P}$ groups was examined by Transwell invasion assay. Cell invasion was decreased in cells of the $\mathrm{C}+\mathrm{A}+\mathrm{P}$ group compared with the Control and HK groups, as assessed by the number of cells invading into the lower surface of the polycarbonic membrane via the matrigel $(\mathrm{p}<0.001)$. (A) SGC7901 cell Transwell invasion assay. (B) U251 cell Transwell invasion assay. (C) The number of cells invading through the matrigel in the Control, HK and C+A+P groups. (D) Protein level of MMP-2, MMP-9 and TIMP-2 in SGC7901 and U251 cells were treated with different shRNAs determined by Western blotting.

the G1/G0 phase fraction of the Control and HK groups was 53 and $48 \%$, respectively, while the $\mathrm{C}+\mathrm{A}+\mathrm{P}$ group increased to $74.2 \%$. The $\mathrm{S}$ phase fraction in the Control and HK groups was 19.6 and $23.8 \%$, respectively, but decreased significantly in the $\mathrm{C}+\mathrm{A}+\mathrm{P}$ group to $9.4 \%$. These results suggest that rAd5-C-A-P can induce the arrest the cells at G1/G0 phases, delay the progression of cell cycle, and inhibit the cell proliferation.

Next, we examined the comparative survival rate by MTT assay. The $\mathrm{C}+\mathrm{A}+\mathrm{P}$ group proliferated at a significantly lower rate than those of the Control and $\mathrm{HK}$ groups (Fig. 4, $\mathrm{P}<0.001$, from day 3 to 6 ), suggesting that downregulation of COX-2, 
Akt1 and PIK3R1 may be involved in the regulation of cell proliferation.

Cell invasion assessed by Transwell invasion assay. To further evaluate the anti-invasive activity of SGC7901 and U251 cells by the rAd5-C-A-P approach, we assessed the inhibitory effect on gastric adenocarcinoma and glioma cells invasion through the Transwell assay. The invasive potential was determined on the basis of the ability of cells to invade a matrix barrier containing mainly laminin and type IV collagen, which are the major components of the basal membrane. Representative micrographs of Transwell filters are shown in (Fig. 5A and B). The number of cells invading through the matrigel in the rAd5-C-A-P treated group was $(26.4 \pm 4.6)$ significantly decreased from those of the Control group $(105 \pm 4)$ and the HK group (102.5 \pm 6.4$)$ in SGC7901 cells (Fig. 5C). In U251 cells, invasive activity was inhibited by $\sim 50 \%$ in the $\mathrm{C}+\mathrm{A}+\mathrm{P}$ group $(28.6 \pm 3.4)$ compared with that of

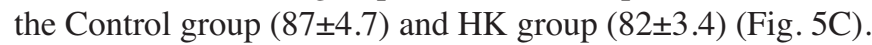
These results suggest that knockdown of human COX-2, Akt1 and PIK3R1 expression by rAd5-C-A-P significantly reduced tumor cell invasion.

Anti-tumor effect of COX-2, Akt1 and PIK3R1 knock-down in a SGC7901 gastric adenocarcinoma xenograft model. Our in vitro experiments demonstrated that the rAd5-C-A-P approach can inhibit cell proliferation efficiently, induce the G1/G0 cell cycle arrest, and prevent the invasion of SGC7901 and U251 cells. Therefore, we further investigated the anti-tumor effect of this approach in vivo using the SGC7901 gastric adenocarcinoma xenograft model and recombinant adenovirus vector-mediated gene therapy as described in Materials and methods. Tumors were established in the right leg of 30 mice using SGC7901 tumor pieces, and, after the tumors reached $\sim 5 \mathrm{~mm}$ in length, each mouse was challenged by in situ injection of PBS $(10 \mu \mathrm{l})$ in the Control $(\mathrm{n}=10), \mathrm{HK}$ $(\mathrm{n}=10)$ and $\mathrm{C}+\mathrm{A}+\mathrm{P}$ groups $(\mathrm{n}=10)$. Adenovirus $(10 \mu \mathrm{l})$ was injected into the subcutaneous tumors using a multi-site injection method. The mean tumor volume at the time of gene therapy was $65.84 \pm 14.51,67.66 \pm 14.74$ and $65.50 \pm 19.48 \mathrm{~mm}^{3}$ in the Control, $\mathrm{HK}$, and $\mathrm{C}+\mathrm{A}+\mathrm{P}$ groups, respectively, with no statistically significant difference among the 3 groups (data not shown). Each of the mice was monitored 10 times, every 2 days, and the tumor volumes were measured and compared (Fig. 6B). The mean volumes of the tumors were 6225.22 \pm $1326.42,5630.596 \pm 982.54$ and $1373.416 \pm 325.21 \mathrm{~mm}^{3}$ after treatment in the Control, $\mathrm{HK}$, and $\mathrm{C}+\mathrm{A}+\mathrm{P}$ groups, respectively (Fig. 6C). COX-2, Akt1 and PIK3R1 knock-down resulted in a statistically significant reduction $(\mathrm{p}<0.001)$ of tumor volumes (22\% for rAd5-C-A-P group) compared with the Control and HK groups.

After the mice were observed for 21 days, tumor samples were taken and paraffin-embedded sections were prepared for immunohistochemical examination using COX-2, Akt1, PIK3R1, PCNA, CyclinD1, MMP-2, MMP-9, TIMP-2 and P53 antibodies. Representative sections from Control, $\mathrm{HK}$ and $\mathrm{C}+\mathrm{A}+\mathrm{P}$ groups, are shown (Fig. 6A). In the Control and $\mathrm{HK}$ groups, highly positive immunoreactivity for COX-2, Akt1, PIK3R1, PCNA, CyclinD1, MMP-2 and MMP-9 was observed. The immunoreactivities were downregulated in the $\mathrm{C}+\mathrm{A}+\mathrm{P}$ group. However, TIMP-2 and P53 immunoreactivities were upregulated in the $\mathrm{C}+\mathrm{A}+\mathrm{P}$ group. The results in vivo were consistent with those observed in vitro.

\section{Discussion}

RNAi technology has advanced from its basic discovery in lower organisms to a powerful genetic tool and a promising biotherapeutic field for a wide array of diseases. Numerous studies have demonstrated the effectiveness of RNAi technology in laboratory research. In addition, the first clinical trials are underway and suggest that RNAi is safe to use in humans (25). RNAi is a regulatory mechanism that uses small dsRNA molecules to direct the homology-dependent control of gene activity (26). In mammalian cells, siRNAs (approximately 21-23 nucleotides in length) are produced from the cleavage of longer short dsRNA precursors by the RNaseIII endonuclease, Dicer (27). The dsRNA can be introduced exogenously or can be expressed intracellularly. Dicer is complexed with the TAR-RNA binding protein (TRBP) and transfers the siRNAs to the RISC, which contains the 'slicing' protein, Argonaute 2 (Ago2). Ago2 cleaves the target mRNA molecules between bases 10 and 11 relative to the 5'-end of the antisense siRNA strand (28). While siRNAs loaded into RISC are doublestranded, Ago2 cleaves and releases the 'passenger' strand leading to an activated form of RISC with a single-stranded 'guide' RNA molecule. This RNA directs the specificity of target recognition by intermolecular base pairing to knockdown this particular gene's expression (29). Rules governing the selectivity of strand loading into RISC are based upon differential thermodynamic stabilities of the ends of the siRNAs $(30,31)$.

In our study, we used COX-2, Akt1 and PIK3R1shRNA RNAi to suppress COX-2, Akt1 and PIK3R1 expression through adenovirus methods. The use of adenovirus has several advantages, including extensive host cell types, high transfection efficiency, and high expression levels, that make this method valuable in gene therapy studies (32). Our results indicate that shRNA targeting of COX-2, Akt1 and PIK3R1 downregulates their expression significantly in a sequencespecific manner, and exerted proliferation and invasion inhibition effects on SGC7901 and U251 cells in vitro and in vivo. To investigate the molecule mechanisms involved, we examined the expression of PCNA, CyclinD1, MMP-2, MMP-9, TIMP-2 and P53 using immunohistochemical methods.

PCNA is a nuclear non-histone protein necessary for DNA synthesis, and is an accessory protein for DNA polymerase- $\alpha$, which is elevated during the G1/S phase of the cell cycle. PCNA expression may be used as a marker of cell proliferation because cells the G1/S phase may be extended when proliferating. In addition, PCNA is essential in nucleic acid metabolism as a component of the DNA replication and repair mechanism $(33,34)$. P53 is an anti-oncogene, and its downregulation or deletion is associated with tumor proliferation and antioncogene inactivation. Some studies have shown that P53 and PCNA expression have a strong correlation. P53 can induce the expression of P21 and glyceraldehyde phosphate dehydrogenase 45 (GAPD45). These 


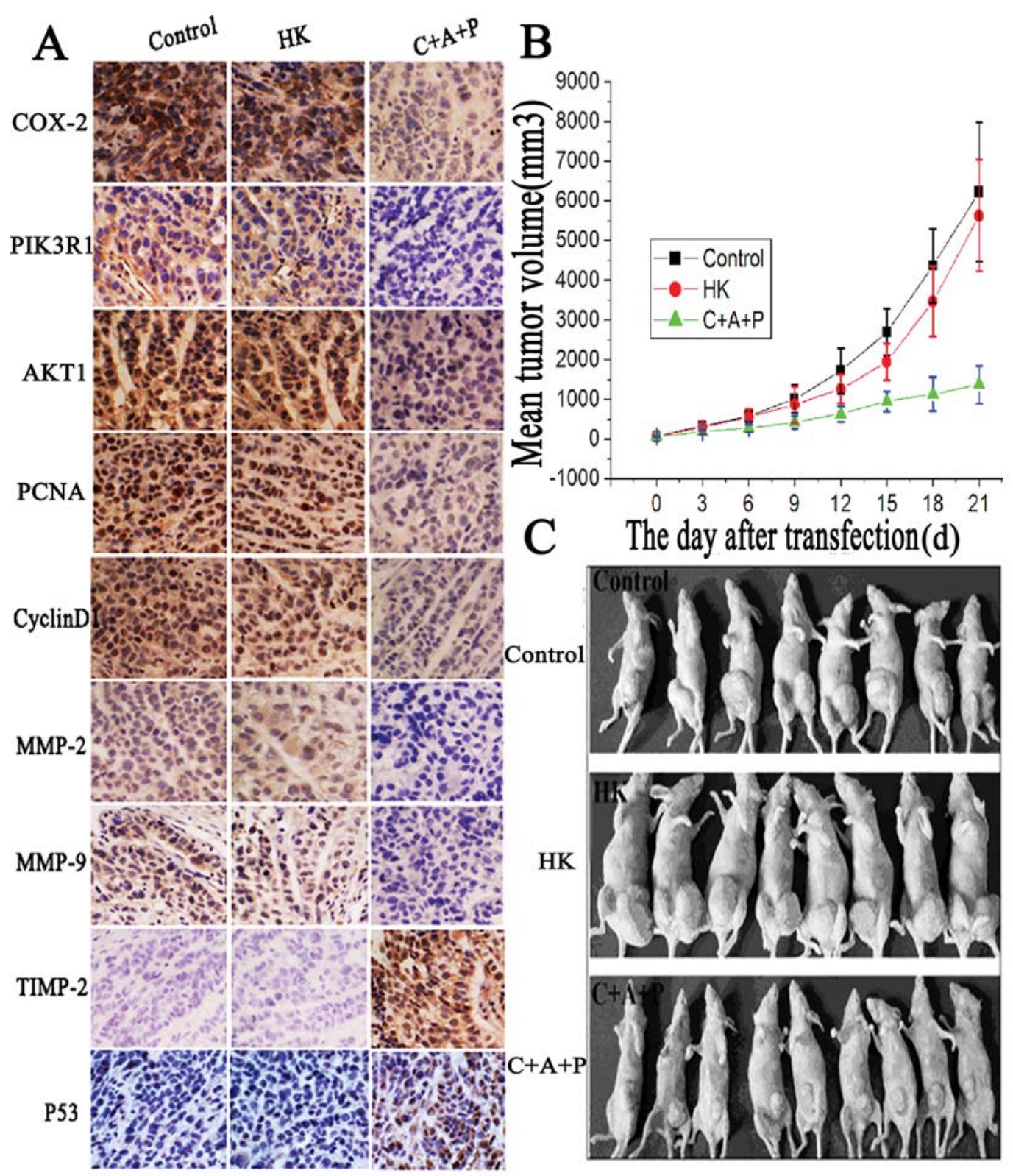

Figure 6. (A) Immunohistochemical examination of COX-2, Akt1, PIK3R1, PCNA, CyclinD1, MMP-2, MMP-9, TIMP-2 and P53 expression in SGC7901 cells. (B) Compared with the Control and HK groups, tumor growth in nude mice in the C+A+P group was inhibited ( $\mathrm{p}<0.001)$ in SGC7901 cells. (C) The volumes of tumors after mice were treated for 21 days.

two proteins bind PCNA and lead to PCNA inactivation and degradation (35). CyclinD1 was overexpressed in various tumors and promotes the G1/S shift leading to cell proliferation. Some studies have demonstrated that P21 inhibits the activation of an induced proliferation inhibition effect on tumor cells $(36,37)$. Therefore, CyclinD1 may also be regulated by P53. The extracellular matrix network functions in supporting cell shape, and coordinating the extracellular signaling system is tightly regulated by a number of proteolytic enzymes, including the family of matrix metalloproteinases (MMPs) $(38,39)$. MMP-2 and MMP-9 are thought to be key enzymes involved in the degradation of type IV collagen, which is a component of the ECM. High levels of MMP-2 and MMP-9 in tissues are associated with tumor cell growth and invasion (40). TIMPs are inhibitors of MMPs, and they bind the activated modality of MMPs and regulate the degradation of ECM. TIMP-2 is the most important member of the TIMP family, and shows a negative correlation between its expression and tumor volume, lymphatic metastasis, and TNM staging (41).

After COX-2, Akt1 and PIK3R1 expression was significantly downregulated, the expression levels of PCNA, CyclinD1, MMP-2 and MMP-9 were decreased dramatically, while that of TIMP-2 and P53 were upregulated. Our results suggest that the activation of COX-2 and PI3K/Akt suppresses the expression of P53 and TIMP-2, resulting in the loss of inhibition and the overexpression of PCNA, CyclinD1, MMP-2 and MMP-9, all of which promote cell proliferation and invasion in tumors. Consequently, a combination of gene therapy and targeting of COX-2, Akt1 and PIK3R1 may be an effective new strategy in targeting molecular therapy of malignant tumors. 


\section{Acknowledgments}

This work was supported by the Natural Science Foundation of Tianjin, Grant nos. 07JCZDJC07700 and 09 JCZDJC17600, and Program for New Century Excellent Talents in University (NCET-07-0615). We thank Dr Daiming Fan for kindly providing SGC7901 gastric cancer cells and members of the Tianjin Laboratory of Neuro-oncology, Tianjin Neurological Institute for their technical assistance.

\section{References}

1. Khalighinejad N, Hariri H, Behnamfar O, Yousefi A and Momeni A: Amir Momeni Adenoviral gene therapy in gastric cancer. World J Gastroenterol 14: 180-184, 2008.

2. Yonemura Y, Wu CC, Fukushima N, Honda I, Bandou E and Kawamura T: Randomized clinical trial of D2 and extended paraaortic lymphadenectomy in patients with gastric cancer. Int J Clin Oncol 13: 132-137, 2008.

3. Tajima Y, Yamazaki K, Makino R, Nishino N, Aoki S and Kato M: Gastric and intestinal phenotypic marker expression in early differentiated-type tumors of the stomach: clinicopathologic significance and genetic background. Clin Cancer Res 12: 6469-6479, 2006.

4. Bernstein E, Caudy AA, Hammond SM and Hannon GJ: Role for a bidentate ribonuclease in the initiation step of RNA interference. Nature 409: 363-366, 2001.

5. Hammond SM, Bernstein E, Beach D and Hannon GJ: An RNA-directed nuclease mediates post-transcriptional gene silencing in Drosophila cells. Nature 404: 293-296, 2000.

6. Bernstein E, Denli AM and Hannon GJ: The rest is silence. RNA 7: 1509-1521, 2001.

7. Fire A, Xu S, Montgomery MK, Kostas SA, Driver SE and Mello CC: Potent and specific genetic interference by doublestranded RNA in Caenorhabditis elegans. Nature 391: 806-811, 1998.

8. Zamore PD: RNA interference: listening to the sound of silence. Nat Struct Biol 8: 746-751, 2001.

9. Sijen T, Fleenor J, Simmer F, Thijssen KL, Parrish S and Timmons L: On the role of RNA amplification in dsRNAtriggered gene silencing. Cell 107: 465-476, 2001.

10. Ristimaki A, Sivula A, Lundin M, et al: Prognostic significance of elevated cyclooxygenase-2 expression in breast cancer. Cancer Res 62: 632-635, 2002.

11. Harris RE, Chlebowski RT, Jackson RD, et al: Breast cancer and nonsteroidal anti-inflammatory drugs: prospective results from the Women's Health Initiative. Cancer Res 63: 6096-6101, 2003.

12. Lala PK, Parhar RS and Singh P: Indomethacin therapy abrogates the prostaglandin-mediated suppression of natural killer activity in tumor-bearing mice and prevents tumor metastasis. Cell Immunol 99: 108-118, 1986.

13. Masferrer JL, Leahy KM, Koki AT, et al: Antiangiogenic and antitumor activities of cyclooxygenase- 2 inhibitors. Cancer Res 60: 1306-1311, 2000.

14. Kundu N and Fulton AM: Selective cyclooxygenase (COX)-1 or COX-2 inhibitors control metastatic disease in a murine model of breast cancer. Cancer Res 62: 2343-2346, 2002.

15. Sheng H, Shao J, Morrow JD, Beauchamp RD and DuBois RN: Modulation of apoptosis and $\mathrm{Bcl}-2$ expression by prostaglandin E2 in human colon cancer cells. Cancer Res 58: 362-366, 1998.

16. Narumiya S, Sugimoto Y and Ushikubi F: Prostanoid receptors: structures properties and functions. Physiol Rev 79: 1193-1226, 1999.

17. Fujino $\mathrm{H}$ and Regan JW: Prostanoid receptors and phosphatidyl 3-kinase: a pathway to cancer? Trends Pharmacol Sci 24: 335-340, 2003.

18. Namba T, Sugimoto Y, Negishi M, et al: Alternative splicing of c-terminal tail of prostaglandin $E$ receptor subtype EP3 determines G-protein specificity. Nature 365: 166-170, 1993.
19. Cully M, You H, Levine AJ and Mak TW: Beyond PTEN mutations: the PI3K pathway as an integrator of multiple inputs during tumorigenesis. Nat Rev Cancer 6: 184-192, 2006.

20. Vivanco I and Sawyers CL: The phosphatidylinositol 3-kinase AKT pathway in human cancer. Nat Rev Cancer 2: 489-501, 2002.

21. Fingar DC and Blenis J: Target of rapamycin (TOR): an integrator of nutrient and growth factor signals and coordinator of cell growth and cell cycle progression. Oncogene 23: 3151-3171, 2004.

22. Duan C, Bauchat JR and Hsieh T: Phosphatidylinositol 3-kinase is required for insulin-like growth factor-I-induced vascular smooth muscle cell proliferation and migration. Circ Res 86: $15-23,2000$.

23. Cartwright JE, Tse WK and Whitley GS: Hepatocyte growth factor induced human trophoblast motility involves phosphatidylinositol-3-kinase, mitogen-activated protein kinase, and inducible nitric oxide synthase. Exp Cell Res 279: 219-226, 2002.

24. Qiu Q, Yang M, Tsang BK and Gruslin A: EGF-induced trophoblast secretion of MMP-9 and TIMP-1 involves activation of both PI3K and MAPK signalling pathways. Reproduction 128: 355-363, 2004.

25. Grimm D and Kay MA: Therapeutic application of RNAi: is mRNA targeting finally ready for prime time? J Clin Invest 117: 3633-3641, 2007

26. Almeida R and Allshire RC: RNA silencing and genome regulation. Trends Cell Biol 15: 251-258, 2005.

27. Zhang H, Kolb FA, Jaskiewicz L, Westhof E and Filipowicz W: Single processing center models for human Dicer and bacterial RNase III. Cell 118: 57-68, 2004.

28. Aagaard L and Rossi JJ: RNAi therapeutics: principles, prospects and challenges. Adv Drug Deliv Rev 59: 75-86, 2007.

29. Tang G: siRNA and miRNA: an insight into RISCs. Trends Biochem Sci 30: 106-114, 2005.

30. Schwarz DS, Hutvágner G, Du T, Xu Z, Aronin N and Zamore PD: Asymmetry in the assembly of the RNAi enzyme complex. Cell 115: 199-208, 2003.

31. Khvorova A, Reynolds A and Jayasena SD: Functional siRNAs and miRNAs exhibit strand bias. Cell 115: 209-216, 2003.

32. Richard CM: The basic science of gene therapy. Science 260: 926-932, 1993.

33. Yang YC, Huang WF, Chuan LM, Xiao DW, Zeng YL and Zhou DA: In vitro and in vivo study of cell growth inhibition of simvastatin on chronic myelogenous leukemia cells. Chemotherapy 54: 438-446, 2008.

34. Oliveira MG, Lauxen Ida S, Chaves AC, Rados PV and Sant'Ana Filho M: Immunohistochemical analysis of the patterns of p53 and PCNA expression in odontogenic cystic lesions. Med Oral Pathol Oral Cir Bucal 13: E275-E280, 2008.

35. Hartwell LH and Kastan MB: Cell cycle control and cancer. Science 266: 1821-1837, 1994.

36. Lebeau A, Unholzer A, Amann G, Kronawitter M, Bauerfeind I and Sendelhofert A: EGFR, HER-2/neu, Cyclin D1, p2l and p53 in correlation to cell proliferation and steroid hormone receptor status in ducta1 carcinoma in situ of the breast. Breast Cancer Res Treat 79: 187-198, 2003.

37. Yamamoto H, Ochiya T, Takeshita F, Toriyama-Baba H, Hirai $\mathrm{K}$ and Sasaki H: Enhanced skin carcinogenesis in Cyclin D1-conditional transgenic mice: cyclin Dl alters keratinocyte response to calcium-induced terminal differentiation. Cancer Res 62: 1641-1647, 2002.

38. Mott JD and Werb Z: Regulation of matrix biology by matrix metalloproteinases. Curr Opin Cell Biol 16: 558-564, 2004.

39. Nagase H, Visse R and Murphy G: Structure and function of matrix metalloproteinases and TIMPs. Cardiovasc Res 69: 562-573, 2006.

40. Cawston TE and Wilson AJ: Understanding the role of tissue degrading enzymes and their inhibitors in development and disease. Best Pract Res Clin Rheumatol 20: 983-1002, 2006.

41. Baker EA, Stephenson TJ, Reed MW and Brown NJ: Expression of proteinases and inhibitors in human breast cancer progression and survival. Mol Pathol 55: 300-304, 2002. 